ORIGINAL ARTICLE

\title{
Results of a programme to improve house staff use of metered dose inhalers and spacers
}

\author{
M Lee-Wong, P H Mayo
}

Postgrad Med J 2003;79:221-225

See end of article for authors' affiliations

Correspondence to: Dr Mary Lee-Wong, Beth Israel Medical Center, 350 East 17th Street, New

York, NY 10003, USA;

mleewong@bethisraelny.org

Submitted 17 June 2002

Accepted

5 November 2002

\begin{abstract}
Purpose: Metered dose inhalers (MDIs) and spacers are used widely in the treatment of asthma. Medical personnel who are responsible for training patients must themselves be proficient with the devices. The proficiency of a group of new medical interns with use of MDI and spacer devices was determined, and improvement in their use of these devices was sought.

Subjects: Fifty six medical interns tested at the start of their first house staff training year.

Methods: The ability of medical interns to use MDIs and spacers was assessed using a visual scoring system before and after a large group lecture emphasising proper device use and once again after an intensive one-on-one training session with an attending physician.

Results: Initially, only 5\% used an MDI perfectly. This improved to $13 \%$ after a lecture and demonstration, and $73 \%$ after an intensive one-on-one session. Almost no new interns could use a collapsible or tube spacer properly initially. This improved to $15 \%$ and $29 \%$ respectively after a lecture. After oneon-one training, correct technique was increased to $69 \%$ for collapsible spacer and $95 \%$ for the tube spacer. Analysis of individual steps of MDI use showed that interns had particular difficulty in coordinating actuation with inhalation. The tube spacer appeared easiest to learn.

Conclusions: Incoming medical house staff have limited ability to use MDI with and without spacers. A large group lecture is relatively ineffective when compared with a one-on-one training session in training with these devices.
\end{abstract}

M etered dose inhalers (MDIs) are used widely in the treatment of asthma, but many patients have difficulty using these devices correctly. ${ }^{1-4}$ Likewise, health care providers have been shown to have suboptimal MDI technique. ${ }^{5}$ It is reasonable to assume that if care providers do not use the MDI correctly, they would have difficulty educating their patients to use them. Clearly, providers who train patients to use an MDI must themselves be able to use the device correctly.

Beth Israel Medical Center (BIMC) in New York City serves an inner city area that has a high prevalence of asthma. Medical house staff at the hospital provide primary medical care to residents of the surrounding community, including large numbers of asthmatic patients. As part of a quality improvement programme targeted at improving asthma care, we decided to train BIMC house staff in the correct use of MDIs and spacers, reasoning that this would improve their ability to treat their patients. This paper describes the results of a programme to training house staff in MDI and spacer use.

\section{METHODS}

The Institutional Review Board of BIMC approved this study. On 6 July 1995, all starting internal medicine interns at BIMC were required to attend a conference without foreknowledge of its content. This one hour period was used to individually test all 56 first postgraduate year intern house staff in their technique of MDI use, with and without spacers. Each house officer was examined individually by one of three testers, all with extensive clinical background in training and scoring MDI use. The examiner was assigned to each intern randomly.

Abbreviations: BIMC, Beth Israel Medical Center; MDI, metered dose inhaler

Table 1 Steps used to assess device score

\begin{tabular}{|c|c|c|c|c|c|}
\hline Step & MDI & & Tube spacer & & Collapsible spacer \\
\hline 1. & Remove cap & 1. & Remove caps and connect MDI to spacer & 1. & Attach mouthpiece to bag \\
\hline 2. & Shake inhaler & 2. & Hold inhaler and spacer together and shake & 2. & Insert MDI into mouthpiece \\
\hline 3. & Hold inhaler upright & 3. & Exhale to FRC or RV & 3. & Shake MDI spacer combination \\
\hline 4. & Tilt head back or keep at level & 4. & Tilt head back or keep at level & 4. & Open spacer bag \\
\hline 5. & Exhale to FRC or RV & 5. & Insert mouthpiece between lips & 5. & Exhale to FRC or RV \\
\hline 6. & $\begin{array}{l}\text { Insert or keep mouthpiece } 2-4 \mathrm{~cm} \text { away from } \\
\text { mouth }\end{array}$ & 6. & Actuate MDI once & 6. & Actuate MDI once \\
\hline 7. & Begin breathing then actuate canister once & 7. & Inhale slowly and deeply & 7. & Place spacer upright between lips \\
\hline 8. & Continue slow, deep inspiration & 8. & $\begin{array}{l}\text { Should hear a hissing sound and not a } \\
\text { whistle }\end{array}$ & 8. & Inhale slowly to TLC \\
\hline 9. & Hold breath for $5-10 \mathrm{sec}$ & 9. & Hold breath for $5-10 \mathrm{sec}$ & 9. & Hold breath for $5-10 \mathrm{sec}$ \\
\hline 10. & Exhale, wait $20-30 \mathrm{sec}$ before second dose & 10. & Wait for $20-30 \mathrm{sec}$ before second dose & 10. & Wait 20-30 sec before next dose \\
\hline 11. & Shake again before a second actuation & 11. & Shake again before a second actuation & 11. & $\begin{array}{l}\text { Shake again before second } \\
\text { actuation }\end{array}$ \\
\hline
\end{tabular}

FRC, functional residual capacity; MDI, metered dose inhaler; RV, residual volume; TLC, total lung capacity. 
Table 2 Percent of house staff using device with perfect technique

\begin{tabular}{llll}
\hline & MDI & $\begin{array}{l}\text { Tube } \\
\text { spacer }\end{array}$ & $\begin{array}{l}\text { Collaspsible } \\
\text { spacer }\end{array}$ \\
\hline No training $(n=56)(\%)$ & 5 & 2 & 0 \\
After large group lecture $(n=48)(\%)$ & $13^{*}$ & $29^{*}+$ & $15^{*}$ \\
After one-on-one training $(n=48)(\%)$ & $73^{* *}$ & $95^{* *} \neq$ & $69 * *$ \\
\hline
\end{tabular}

${ }^{*} p<0.05$ when compared with no training with same device; $* * p<0.05$ when compared with large group lecture with same device; $+p<0.05$ when compared with MDI and collapsible space device; $\dagger p<0.05$ when compared with $\mathrm{MDI}$ and collapsible spacer
and same training level; $\neq p<0.05$ when compared with MDI and collapsible spacer and same training level.

Each intern used in random sequence a MDI device, a MDI with collapsible spacer (Inspirease, Key Pharmaceuticals, Kenilworth, NJ) and a MDI with tube spacer (Aerochamber, Forest Pharmaceuticals, St Louis, MO). An MDI filled with placebo medication was used throughout. House staff were scored using a system described in a previous study that evaluated MDI and tube spacer use. ${ }^{7}$ Collapsible spacer use was evaluated using a similar strategy (table 1). The authors developed the steps used to score the collapsible spacer use. At the first session, the house staff were graded on their technique and no attempt was made to correct or train house staff in proper device usage. The testing area was designed so that house staff could not observe each other during testing, nor could they see the devices before testing. They left the testing area immediately after scoring. To validate the visual scoring system, all three examiners scored several subjects simultaneously, and their scores were compared. There was uniform scoring by the observers, so only one examiner examined each house officer.

Ten days later, the same group attended a mandatory conference on asthma management. At this lecture, one of the original examiners reviewed proper use of the MDI with and without spacer devices in detail. This included repeated demonstration by the speaker of correct use in front of the house staff audience. The week after this group session, all house staff received written directions on correct MDI and spacer use attached to their paycheck to reinforce what was taught in the lecture.

During August 1995, all available intern house staff were contacted individually by one of the three original examiners and given a one-on-one training session. The same examiner did all scoring and training in the first and second follow up session. At the start of the session, each trainee was given a placebo MDI, collapsible spacer, and tube spacer; and asked to demonstrate MDI and spacer technique based on what they had learned from the handout and large group lecture. After scoring using their own devices, they were trained exhaustively to use the MDI, with and without spacers. Each session lasted at least 20 minutes, and did not end until the intern could repeatedly demonstrate perfect technique with all devices.

In October 1995, the same examiner scheduled a final grading session to evaluate the device scores for all available house staff who had undergone initial one-on-one training. After the standard visual scoring of MDI and spacer technique, remedial training was given, if necessary.

\section{Statistical analysis}

Data were analysed with the $\chi^{2}$ method applied to $2 \times 2$ contingency tables. A significance level of $5 \%=0.05$ was used throughout. The null hypothesis in all cases was that the observed frequencies were from the same distribution (that is, there was no improvement in the performance of correct steps). The alternative hypothesis was that the observed frequencies were from different distributions (that is, there
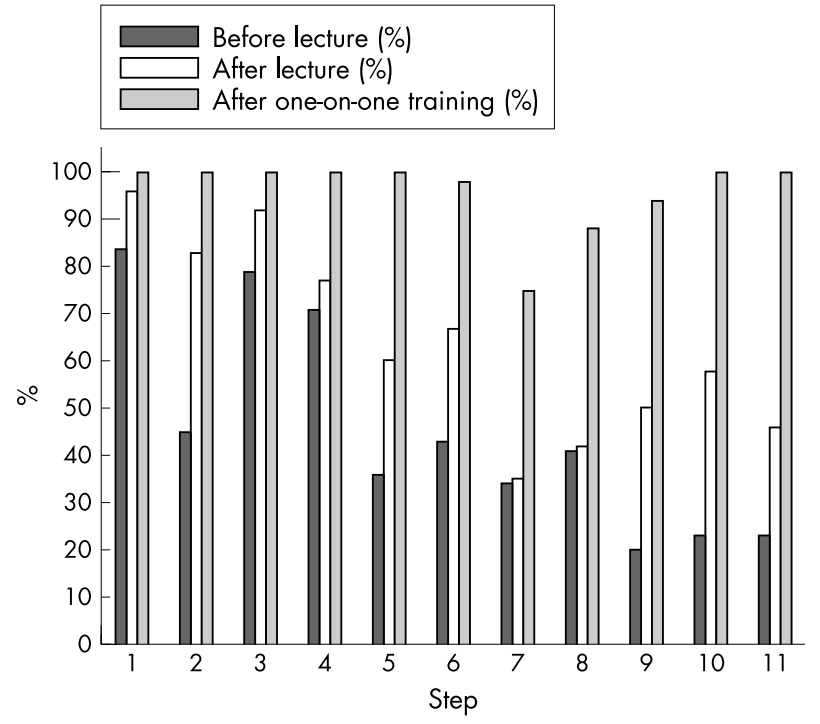

Figure 1 Percentage of house staff correctly performing individual steps of MDI use. Before lecture to after lecture improvement scores significant at $p<0.05$ in all cases with the exception of steps 7 and 8. After lecture to after one-on-one improvement in individual step scores significant at $p<0.05$ in all cases with the exception of step 1 .

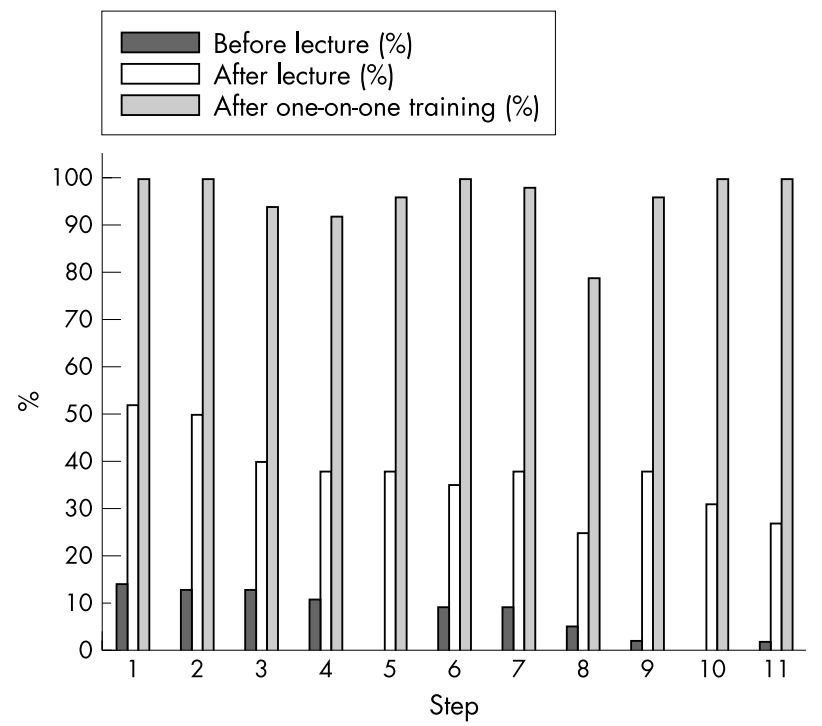

Figure 2 Percentage of house staff correctly performing individual steps of collapsible spacer use. Before lecture to after lecture improvement in individual step scores significant at $\mathrm{p}<0.05$ for all steps. After lecture to after one-on-one improvement in individual step scores significant at $p<0.05$ for all steps.

was a significant improvement in the performance of correct steps). In this case, the $\chi^{2}$ method was two sided. The data, however, were unidirectional. This would indicate that the alpha of $5 \%$ is actually smaller making the conclusions more compelling.

\section{RESULTS}

Fifty six medical interns were available for initial testing of MDI and spacer technique. One and one half weeks later, 52 were able to attend the large group lecture and demonstration of device use. At the first follow up individual training session, 48 interns were available, and on the second follow up training session these same 48 interns were retested for MDI and spacer technique. All of them had attended the large group lecture. Interns who were not available had conflicts caused by work schedules and vacations. 

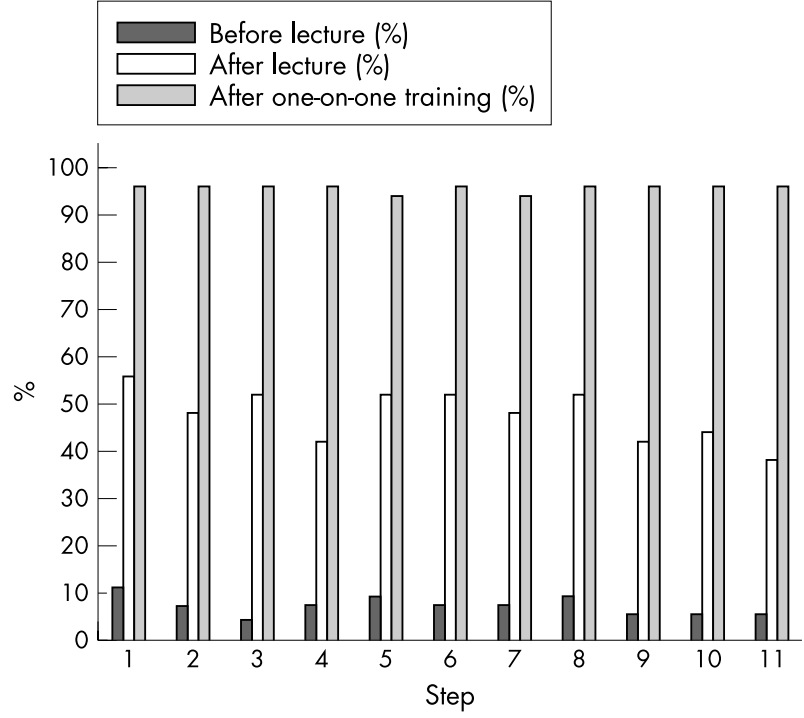

Figure 3 Percentage of house staff correctly performing individual steps of tube spacer use. Before lecture to after lecture improvement in individual step scores significant at $p<0.05$ for all steps. After lecture to after one-on-one improvement in individual step scores significant at $\mathrm{p}<0.05$ for all steps.

The percentage of house staff able to use the devices with perfect technique is shown in table 2 . Results of the scores for each step of use are presented in figs 1, 2, and 3 for MDI, collapsible spacer, and tube spacer respectively. To identify and compare specific steps for each MDI method, data are expressed as percentage of house staff who completed each step correctly as the number of house staff in the test groups before and after training differed. At the time of the one-on-one session, 21 of 48 interns recalled that they received a handout on MDI and spacer use attached to their pay stubs and 10 reported reading it. Since the handout was stapled to their paychecks and all paychecks were picked up and signed for, all 48 interns did receive the handout. None stated that they found it useful. Informal discussion with house staff after the final training session elicited a very favourable response to one-on-one sessions, as well as the repeated comment that "hands on" training with the actual devices was very useful in acquiring good technique. Many stated that hearing about how to use these devices in lectures, or reading about how to use them, was either not useful or inadequate compared with actual training with the devices. Some interns commented that having their own devices in hand was useful for patient training purposes.

\section{DISCUSSION}

No matter how efficacious the medication in an MDI may be, poor inhaler technique may render it ineffective. ${ }^{8}$ Care providers have a responsibility to train their patients in correct MDI use. Unless the care provider can use an MDI correctly, they cannot be expected to train their patients properly. We chose to focus training efforts on house staff, as they provide much of the primary care to our patient population. We felt that every medical house officer should be able to use an MDI and spacer perfectly as a necessary first step in being able to train their patients. Our intent was to train all house staff with perfect technique-that is, a perfect visual score.

Very few new house staff could use any of the devices perfectly (see table 2). After a large group lecture and handout, only $13 \%$ and $15 \%$ of house staff had perfect technique with the MDI and collapsible spacer respectively, while $29 \%$ could use the tube spacer. We conclude that a lecture format and handout information was not particularly effective in yielding perfect technique. Several weeks after the one-on-one training, at least two thirds of the house staff could demonstrate perfect MDI and collapsible spacer use, and $95 \%$ could use the tube spacer perfectly. Compared with a lecture alone, the addition of one-on-one training with the devices was very effective. Compared with the other devices, the percentage of house staff achieving a perfect skill level with the tube spacer was significantly improved after the lecture and one-on-one session. We emphasise that all interns were required to demonstrate perfect device technique at the end of the first one-on-one session. Retesting occurred one to two months after the oneon-one session, so the last testing session reflects the durability of training effect.

Although we attached written instructions regarding device use to the paychecks of all interns in order to guarantee that they received them, most interns had no recollection of receiving the handout, and those who did either did not read it or found it not to be helpful. We conclude that written instructions appeared to an ineffective means of training house staff to use the devices.

The correct use of an MDI may be broken down into a series of discrete, easily scorable steps. The total score of MDI use may be misleading, as it is possible to achieve a high total score and yet not deliver any medication to the lower airways. For example, a house officer might perform all steps correctly using an MDI except for step number 7-that is, not coordinating actuation with inhalation. The total score would be 10 out of 11 , and yet there would be no drug delivery to the airways. Total score may not reflect adequacy of technique. For this reason, it is important to report the individual steps of MDI use rather than the total score. This permits analysis of patterns of device use in a manner that is clinically relevant and useful for training. Clearly, a perfect performance score is the desirable educational outcome, and a perfect score is the best final arbiter of success.

Frequently, interns could perform some steps of solo MDI use without training - for example, removal of the MDI cap (step 1). Their main deficit was in coordination of actuation with inhalation and with completing a deep inspiration followed by breath hold (steps 7 and 8 ). The lecture had positive influence on many features of MDI use, except for the coordination of actuation with a slow deep inspiration. (Step 7). One-on-one training led to further improvement, but the inspiratory coordination was only achieved by $75 \%$ when measured several weeks after one-on-one training to perfect technique level. The difficulty parallels that found in training patients, ${ }^{1}$ and suggests that training of house staff should concentrate on this aspect of MDI use.

No starting intern could use the collapsible spacer perfectly and few could perform any of the individual steps. The lecture resulted in improvement in all steps of use, and the one-onone session had further positive effect on all steps measured. Few starting interns could perform any steps to use the tube spacer; and the lecture effected some improvement in all steps. The one-on-one session improved all steps to a major extent. House staff appeared to retain technique with the tube spacer more readily than the other two devices. This may reflect the fact that the device does not require close coordination of actuation and inhalation. Also, the device is simpler in design than the collapsible spacer.

Several studies have measured medical personnel's use of MDI and spacers. Kelling et al evaluated solo MDI use in house staff and attending physicians. ${ }^{9}$ They found that $40 \%$ of study participants could perform more than four of seven steps with correct technique. Only $10 \%$ of house officers and none of attending staff performed perfectly. Guidry et al reported 65\% of house officers, and 50\% of non-pulmonary physicians performed at least four of seven steps correctly with solo MDI, while nurses and respiratory therapists had superior performance. $^{5}$ Mas et al reported only $10 \%$ of paediatric residents with at least nine months of postgraduate training 
could use a solo MDI with perfect technique. ${ }^{6}$ Havania et al, from whom our scoring method derives, found that many house staff lack rudimentary skills with inhalational deivices. ${ }^{7}$ All groups had particular difficulty with step 7, the coordination of actuation with inhalation using the solo MDI. Similar results were found with tube spacers, as we found as well. Respiratory therapists had better technique than house staff or nurses. Kesten et al reported similar results in pharmacists using the three devices. ${ }^{10}$ Interiano et al reported that $43 \%$ of medical house staff had good technique, defined as performance of five or six steps out of a possible seven with solo MDI. ${ }^{11}$ Amirav et al found that paediatric house staff had significant deficiencies in using MDI and spacers. ${ }^{12}$ Plaza et al found that $15 \%$ of nurses and $28 \%$ of physicians showed correct inhalation technique. ${ }^{13}$ Similarly, Tsang et al, O'Donnell et al, and Chafin et al describe similarly low rates of adequate MDI technique by medical personnel..$^{14-16}$

Two studies have investigated methods of training house staff in MDI and spacer use. Resnick et al found that 26\% of pediatric house staff had perfect MDI technique on initial testing without any improvement in percent with perfect score two months after a one-on-one training session. Interestingly, some house staff with perfect technique on first testing actually had a decrement in technique on second testing. ${ }^{17} \mathrm{~A}$ controlled study by Rebuck et al showed significant improvement in house staff scores with MDI, tube spacer, and dry powder inhaler after an eight month period after a nurse directed education session when compared with an untrained house staff group. ${ }^{18}$ Our measurement methods are similar to theirs. Our results confirm previous work in this area and add additional information regarding the collapsible spacer device.

This study has methodological limitations. It was an observational study, and was neither blinded nor controlled. The person who assessed technique was also the house staff trainer, an obvious source of bias. The study lacks a control group; ideally, we would have had a group of interns who received no training whatsoever, in order to compare them to the lecture and intensive training session. Perhaps the improvement in technique might have occurred without any intervention, since more advanced residents and other clinical faculty might have trained the incoming interns informally and accomplished the same effect without an organised teaching effort. While we acknowledge the lack of control group, we emphasise that the reason we initiated the training was because house staff in previous years appeared to have very poor technique, even well into their residency. The training programme was designed specifically to remedy this problem. House staff had not appeared to learn the devices in an unstructured training environment.

Another methodological flaw is that we did not compare the lecture format directly against the one-on-one training method alone. Ideally, we would have compared an untrained control group, with groups trained with a lecture alone and another group with one-on-one training alone. We believe that the lecture was not essential to the success of the one-on-one session, since we had been unable to train house staff by lecture alone in prior years. In addition, our data collection methods could have been improved by videotaping each testing session to allow for blinded scoring by several observers. Gray et al report issues related to interater and intrarater reliability in the evaluation of MDI technique. ${ }^{19}$ The addition of a flow and actuation sensor to the MDI and spacer would also have allowed completely objective measurement of certain aspects of inhaler use. ${ }^{14}$ Finally, four interns out of the original group of 52 tested were not trained or further tested. Properly, this group could have been included into statistical analysis, but to simplify methodology we have chosen not to do this. We doubt that these four subjects would have altered our results.

Our study leaves unanswered questions. First, does improvement of house staff proficiency in the use of the MDI translate into improved patients' ability to use these devices? Clearly, physicians must themselves be proficient before they can train a patient to use the device. However, mere proficiency does not guarantee that the physician can successfully teach the use of an MDI to a patient, since transfer of knowledge requires a complex set of communication skills which we did not examine. Second, is the training durable? We did not test house staff technique beyond four weeks after one-on-one training, and it is possible that proficiency might decline. We found a decrement in technique in several house officers four weeks after the one-on-one training session, similar to that found in other studies of house officers and patients. We speculate that good MDI and spacer technique will remain with the house officers who use their knowledge regularly to train patients. Those who do not will probably experience a decline in ability to use the devices. Finally, it is possible that alternative training may have similar effect. One-on-one teaching is very labour intensive and it is possible that several house officers be trained simultaneously.

In summary, faculty who train medical houses staff should anticipate that new interns have minimal ability to use metered dose inhalers and spacers properly. A group lecture may improve this situation, and individualised training is very effective, but not completely so. Technique of using the tube spacer appears to be easier to learn than the collapsible spacer. A significant number of house officers will continue to have problems coordinating inhalation and actuation when using an MDI without a spacer. A small number of house staff has continuing problems in learning the correct technique, despite intensive individualised instruction. This programme was labour intensive for the faculty, but can be justified in training programmes that serve areas of high asthma prevalence. Further research is needed to determine how best to train house staff in transferring newly acquired knowledge to patients with asthma.

\section{ACKNOWLEDGEMENT}

This study received no financial support from any source.

\section{Authors' affiliations}

$M$ Lee-Wong, Division of Allergy and Immunology, Beth Israel Medical Center, Albert Einstein College of Medicine, New York

P H Mayo, Division of Pulmonary and Critical Care, Beth Israel Medical Center, Albert Einstein College of Medicine, New York

\section{REFERENCES}

1 DeBlaquiere $\mathbf{P}$, Christensen DB, Carter WB, et al. Use and misuse of metered dose inhalers by patients with chronic lung disease. Am Rev Respir Dis 1989;140:910-6.

2 Crompton GK. Problems patients have using pressurized aerosol inhalers. Eur J Respir Dis 1982;63(suppl 119):101-4.

3 Pederson S, Frost L, Arnfred T. Errors in inhalation technique and efficiency in inhaler use in asthmatic children. Allergy 1986;41:1 18-24.

Shim C, Williams MH. The adequacy of inhalation of aerosol from canister nebulizers. Am J Med 1980;69:891-4

5 Guidry GG, Brown WD, Stogner SW, et al. Incorrect use of metered dose inhalers by medical personnel. Chest 1992;101:31-3.

6 Mas JC, Resnick DJ, Firschein DE, et al. Misuse of metered dose inhalers by housestaff members. Am J Dis Child 1992;146:783-5.

7 Havania NA, Wittman R, Kesten S, et al. Medical personnel's knowledge of and ability to use inhaling devices. Metered-dose inhalers, spacing chambers, and breath-actuated dry powder inhalers. Chest 1994; 105:111-16.

8 Lindgren S, Bake B, Larsson S. Clinical consequences of inadequate inhalation technique in asthma therapy. Eur J Respir Dis 1987-70.93-8.

Kelling JS, Strohl KP, Smith RL, et al. Physician knowledge in the use of Kelling JS, Strohl KP, Smith RL, et al. Physician
canister nebulizers. Chest 1983;83:612-14.

10 Kesten S, Zive K, Chapman KR. Pharmacist knowledge and ability to use inhaled medication delivery systems. Chest 1993;104:1737-42.

11 Interiano B, Guntupalli KK, Metered-dose inhalers. Do health care providers know what to teach? Arch Intern Med 1993:153:81-5.

12 Amirav I, Goren A, Pawlowski N. What do pediatricians in training know about the correct use of inhalers and spacer devices? J Allergy Clin Immunol 1994;94:669-75. 
13 Plaza V, Sanchis J. Medical personnel and patient skill in the use of metered dose inhalers: a multicentric study Respiration 1998:65:195-8. 14 Tsang $K$, Lam W, lp $M$, et al. Inability of physicians to use metered-dose inhalers. J Asthma 1997;34:493-8.

15 O'Donnell J, Birkinshaw R, Burke V, et al. The ability of A\&E personnel to demonstrate inhaler technique. J Accid Emerg Med 1997;14:163-4.

16 Chafin CC, Tolley E, Demirkan K, et al. Effect of a brief educational intervention on medical students' use of asthma devices. J Asthma $2000 \cdot 37: 585-8$.
17 Resnick DJ, Gold RL, Lee-Wong M, et al. Physicians' metered dose inhaler technique after a single teaching session. Ann Allergy Asthma Immunol 1996;76:145-8.

18 Rebuck DA, Dzyngel B, Khan K, et al. The effect of structured versus conventional inhaler education in medical house staff. J Asthma 1996;33:385-93

19 Gray SL, Nance AC, Williams DM, et al. Assessment of interrater and intrarater reliability in the evaluation of metered dose inhaler technique. Chest 1994;105:710-14.

\section{FELLOWSHIP AFFAIRS}

\section{Dr Barry Hoffbrand}

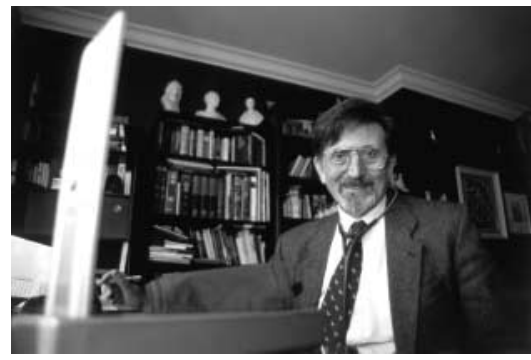

ast year, Barry Hoffbrand demitted office as a member of the editorial board of the Fellowship of Postgraduate Medicine on retiring from full time clinical practice.

Barry joined the editorial board 30 years ago; for 14 of these (1980-94), he was editor of this journal during a formative period and he created a viable and successful clinical educational journal to rival the best. It is a reflection of his industry, dedication to quality and accuracy, and his wise editorial judgment that the journal occupies its present successful position in the medical publishing world.

Originally a source of printed lectures which had been organised by the Fellowship after the first world war, the journal has evolved and during Barry's editorial tenure not only has there been a flowering in original, review, and special topic papers but a number of supplements on therapeutic and pharmacological advances have been published improving both circulation and finances of the journal. In addition, Festschrifts-for which he chose his editors carefully-have been a feature as supplements to the monthly publications (for example, that for Professor Margaret Turner-Warwick was the fourth supplement to volume 64) and supplements reporting the conferences organised by the Fellowship on European Postgraduate Medical Education.

In the period when the Fellowship offices were high up at St Andrew's Place, it was a familiar late afternoon sight to see Barry, both arms full of manuscripts-accepted/not accepted/for revision-arriving up the steep, narrow stairs to Jean Coops' office where the journal was assembled and proofread. This was concurrent with his busy clinical workload at the Whittington Hospital and maintaining his work at officer level in the clinical section of the Royal Society of Medicine, and a medicolegal practice.

He maintained firm views on the presentation and display while keeping a detailed grasp of the publisher's needs. I like to think that he has ensured the success of our unique publication which has no specialist association to feed or support it.

He was a valued, at times outspoken, member of Council cutting logically through vague or deceptive proposals and his sense of historical continuity was well illustrated by the 60th Anniversary Issue of October, 1985 particularly with his editorial and choice of contributors.

He has given of his personal time and energy generously over these 30 years and there are many to whom the Fellowship owes much, but none has done more to ensure the success of the journal in particular than Barry and it is a pleasure at this time to thank him for that and wish him well in his future professional interests._Michael Nicholls, Fellowship of Postgraduate Medicine 